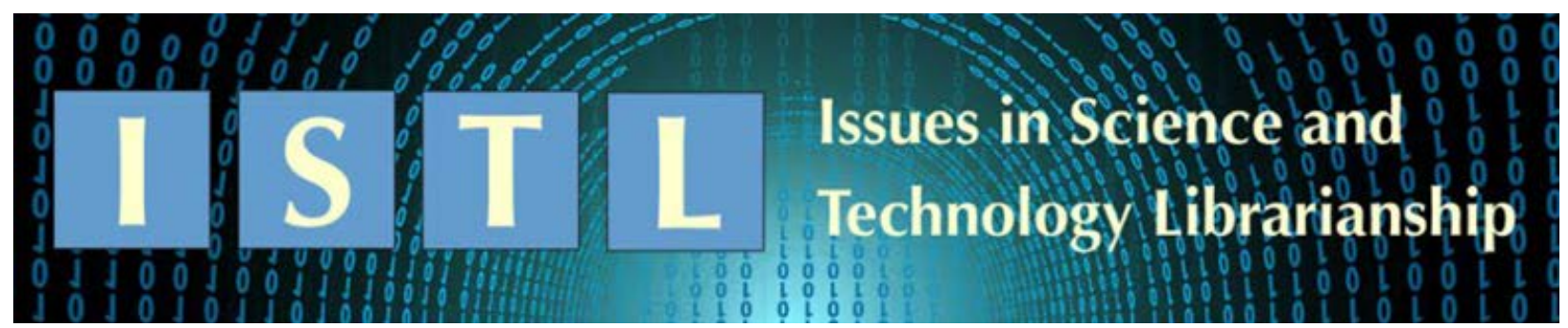

\title{
Investigating Science Researchers' Presence on Academic Profile Websites: A Case Study of a Canadian Research University
}

\author{
Li Zhang \\ University of Saskatchewan Library. \\ li.zhang@usask.ca \\ Chen Li \\ Department of Chemical and Biological Engineering \\ University of Saskatchewan \\ chl177@mail.usask.ca
}

\begin{abstract}
Researchers are increasingly using academic profile websites (APWs) to organize and showcase their research outputs. Using the faculty at the science departments of the University of Saskatchewan, Canada as the study object, this research explores how science researchers used four APWs: ResearchGate, Google Scholar Citations, Academia.edu, and ORCID. It was found that $78 \%$ of the researchers had established at least one academic profile, with ResearchGate being the most popular platform, Google Scholar Citations the second, followed at some distance by ORCID and Academia.edu. A high percentage of ORCID users did not list any of their publications, meaning their presence on ORCID was merely symbolic. We also found that the social interaction functions provided by ResearchGate were not well adopted. Findings from this study call for improvements to the workflow of adding publications to ORCID profiles. In the meantime, in order to improve the effectiveness of ORCID, librarians may consider providing specific instructions on how to add publications to ORCID profiles from different sources as part of their promotional campaign of APWs.
\end{abstract}

\section{Introduction and Literature Review}

Academic profile websites (APWs) are online platforms that allow researchers to create professional profiles and organize and showcase their research outputs. Examples of APWs include Google Scholar Citations, ResearchGate, Academia.edu, and ORCID (Open Researcher and Contributor ID). These online APWs have emerged as alternatives to established scholarly communication channels, such as emails or listservs. They have gained popularity in the research communities, largely because of their perceived value as vehicles for boosting scholarly impact 
and thus advancing research careers. As of this date, there are 15 million users in ResearchGate (ResearchGate 2019), 108 million in Academia.edu (Academia.edu 2019), and 7 million in ORCID (ORCID 2019a). Although the exact number of profiles in Google Scholar Citations is not available, an earlier study reported that there were about 600,000 profiles on this platform in 2015 with an annual growth rate of 101\% (Ortega 2015a). Therefore, it is estimated that the current number of profiles in Google Scholar Citations may be comparable to those in ResearchGate and ORCID.

Based on the success of general social networks such as Facebook and Twitter, some of the APWs (e.g., ResearchGate and Academia.edu) have also developed functions of social networking, allowing researchers to interact with others having similar interests in order to enhance knowledge sharing and research collaboration. This type of profile website is called academic social network (ASN). Researchers have begun to adopt the interaction functions available in ASNs for research-related activities (Gruzd \& Goertzen 2013; Van Noorden 2014).

With the growing popularity of online APWs in recent years, an increasing number of studies have explored the effect of these platforms on researchers. The literature on this topic has mainly concentrated on two themes. One theme explored why researchers used APWs. For example, a study of the usage of social networks among social science scholars found that information gathering ranked as the most important reason for using these websites, followed by selfpromotion, networking, and collaboration (Gruzd \& Goertzen 2013). Meishar-Tal and Pieterse (2017) surveyed faculty in three academic institutions in Israel and found that researchers used ASNs mainly for self-promotion and document downloading, less frequently for information sharing, and rarely for interaction. Wu et al. (2017) interviewed 15 researchers in the United States in various disciplines to discover their motivations for using APWs and found that the major motivations included finding literature, documenting and promoting publications, identifying collaborators, and interacting with peers. More recently, Kjellberg and Haider (2018) conducted focus group studies of 27 researchers in different disciplines, genders, and seniority levels in Swedish universities. They concluded that ASN sites were predominately perceived, and used as, tools for promoting research publications, and, to a lesser extent, for public engagement activities or career advancements. Furthermore, Kjellberg and Haider (2018) revealed that, when researchers promoted their own publications on ASNs, they not only made their research outputs more visible, but also made themselves more visible as researchers, thus ultimately increasing their academic reputation, which was described as the "main currency for the academic" (Becher 1989). In summary, all these studies seem to suggest that self-promotion of research outputs and full-text document downloading are the main reasons for using APWs and collaboration and interaction seem to be less important. However, it should be pointed out that uploading the full-text of published articles on ASNs may violate the copyrights of publishers (Harington 2017). Thus, when researchers use ASNs to download the full-text of articles, they may risk themselves in issues around copyright infringement.

The other theme found in the literature was the presence of researchers on APWs. Mas-Bleda et al. (2014) investigated the presence of 1517 highly-cited European researchers on several platforms, including Google Scholar Citations and Academia.edu. They found that the usage of online profile websites by these top researchers was very low; only $9.4 \%$ of the researchers had a profile on Google Scholar Citations and just 1.5\% on Academia.edu. Similarly, Ortega (2015b) 
also reported a low usage of APWs among 11,000 Spanish researchers in various disciplines: only 39\% had created an academic profile, with ResearchGate being the most popular (29\%), followed by Google Scholar Citations (11\%), Mendeley (7\%), and Academia.edu (6\%). However, several more recent studies revealed a higher presence rate on APWs. For example, Míguez-González et al. (2017) analysed the presence and activities of 78 scholars in the field of communication studies in three Portuguese universities and found a presence rate of $60 \%$ on ResearchGate and Academia.edu. They also noticed that $15 \%$ of the researchers were symbolic researchers, i.e., researchers that only created a name profile without providing a publication list or other further information. Most recently, Martín-Martín et al. (2018) studied bibliometricians' uptake of popular APWs including Google Scholar Citations, ResearcherID (an APW developed by Web of Science), ResearchGate, and Mendeley. Of the 811 bibliometricians who had a profile in Google Scholar Citations, 67\% had established a profile in ResearchGate, followed at some distance by Mendeley (41\%) and ResearcherID (35\%). They also found that a significant percentage of academic profiles in Mendeley (17\%) and ResearcherID (34\%) were symbolic. Although the presence rates reported in the latter two studies were higher, it should be noted that the study objects (communication studies researchers and bibliometricians) are generally considered to be researchers who are more familiar with new online academic communication platforms, and thus they may be more likely to use these tools than researchers in other fields.

Although ORCID (2018) states that it is not an academic profile system (ORCID 2018), it does provide researchers with functions similar to those in an APW, such as publication listing, employment history, education and qualifications. Therefore, we refer to ORCID as an APW in this study. While several APWs already existed before ORCID was launched in 2012, they are proprietary (Haak et al. 2012). In contrast, ORCID is a community-driven non-profit organization sponsored by the international research community, including research organizations, publishers, funding agencies, professional associations, and other stakeholders. One of ORCID's primary goals is to identify research outputs of scholars and solve name ambiguity issues by assigning researchers with unique 16-digit author identifiers. Due to this focus, ORCID does not provide social networking functions or impact measurements (e.g., citation metrics or altmetrics). As of this date, there are 1106 member organizations (ORCID 2019b). An increasing number of publishers and funding agencies have also incorporated ORCID in their work processes to make it easier for each researcher to maintain, update, and provide a complete list of their publications.

While a growing number of studies of APWs have been conducted on platforms such as Google Scholar Citations, ResearchGate and/or Academia.edu, very few have included ORCID. Of the limited studies, Mikki et al. (2015) compared the use of ResearchGate, Academia.edu, Google Scholar Citations, and ORCID by researchers in a Norwegian university. They found that while $37 \%$ of the researchers had at least one profile, ResearchGate was the most popular site (30\%), followed by Google Scholar Citations (8\%), while Academia.edu and ORCID only had $4 \%$ and $3 \%$ presence, respectively. In another study, Tran and Lyon (2017) surveyed the use of APWs in a US research university and found low levels of awareness of these resources. In terms of popularity of the profile websites, they found that the most used ones included ResearchGate (64\%), Google Scholar Citations (54\%), Academia.edu (24\%), and ORCID (15\%). The limited evidence suggests that, although setting up ORCID profiles may provide many benefits to researchers and to the research community, its acceptance is still low. 


\section{Objectives}

As discussed above, while there are increasing number of studies on APWs in Europe, studies in North America, particularly in Canada, are sparse. Different countries may have different academic cultures, which will impact how researchers communicate, collaborate, and disseminate their research. Therefore, the uptake of APWs may vary by geographic area. This study will explore the usage of APWs among Canadian science researchers, hoping to gain a more complete understanding of the effects of APWs on scholarly communications. Specifically, this research will investigate the following questions:

- What is the percentage of science researchers who have established a research profile on APWs? Which website is the most popular?

- What are their activities on APWs?

- Are there differences in the activities from different groups (i.e., disciplines, professional ranks)?

\section{Methods}

We chose the faculty members at the science departments of the University of Saskatchewan (USask), Canada, as study objects. USask is one of the 15 research-intensive universities in Canada (U15 2019), and there are six science departments at the University: Departments of Biology, Chemistry, Computer Sciences, Geological Science, Mathematics \& Statistics, and Physics \& Engineering Physics.

For APWs, we selected ResearchGate, Academia.edu, Google Scholar Citations, and ORCID. The former three platforms seemed to be the most used APWs among researchers outside Canada according to our review of the literature. We also included ORCID in this study. ORCID Consortium in Canada (ORCID-CA) was established in 2016 to promote and facilitate the adoption of this tool. With 35 institutional members, its main goals are to have an ORCID identifier for all active researchers in Canada and to integrate ORCID into major Canadian grant management and CV systems (ORCID-CA 2019). The inclusion of ORCID in this study will allow us to find out how individual researchers have adopted this platform.

We retrieved information of the science faculty members from their departmental websites and recorded name and rank (i.e., assistant professor, associate professor, or professor). We only included faculty at the rank of the professoriate. Other types such as lecturer, emeritus, or adjunct were not included. If the rank of a faculty member was not listed on the website, we contacted the department to clarify the information. There were 129 faculty members included in this study.

We then searched ResearchGate, Academia.edu, Google Scholar Citations, and ORCID to find if the faculty members had established profiles on each of the sites, and recorded relevant information provided on these sites. In some cases, if we could not verify whether the profile found on the sites was that of the specific researcher, we recorded the availability of the researcher's profile as "not available." Table 1 lists the information recorded on each APW. The search was first carried out by CL and then checked by LZ. It was completed in August 2018. 
Table 1. Information recorded on each APW.

\begin{tabular}{|c|c|c|c|c|}
\hline Information Recorded & ResearchGate & Academia.edu & $\begin{array}{l}\text { Google Scholar } \\
\text { Citations }\end{array}$ & ORCID \\
\hline number of publications & $\mathrm{x}$ & $\mathrm{x}$ & $\mathrm{x}$ & $\mathrm{x}$ \\
\hline number of projects & $\mathrm{x}$ & & & \\
\hline views $^{a}$ & $\mathrm{x}$ & $\mathrm{x}$ & & \\
\hline followers & $\mathrm{x}$ & $\mathrm{x}$ & & \\
\hline following & $\mathrm{x}$ & $\mathrm{x}$ & & \\
\hline $\begin{array}{l}\text { number of questions asked by } \\
\text { the researcher }\end{array}$ & $\mathrm{x}$ & & & \\
\hline $\begin{array}{l}\text { number of answers by the } \\
\text { researcher }\end{array}$ & $\mathrm{x}$ & & & \\
\hline
\end{tabular}

a view is counted each time when a profile, a publication or any part of the profile is clicked, as defined by ResearchGate and Academia.edu

\section{Results}

\section{Presence Rate on APWs}

Out of the 129 members included in this study, 100 (78\%) had established at least one academic profile. The details of the presence of faculty on each APW by department are shown in Table 2. The Department of Computer Science had the highest presence rate on APWs, with 96\% of the faculty having at least one profile. The departments with the least presence on APWs were Chemistry (65\%) and Mathematics \& Statistics (68\%). In general, as shown in Figure 1, ResearchGate was the most popular APW among all the researchers, with 81 (63\%) having set up a profile on this site, followed by Google Scholar Citations with 62 profiles (48\%). It is encouraging to know that, while ORCID was only established in 2012, it had gained a presence rate of $29 \%$ (38 profiles). Academia.edu had the lowest presence rate of $23 \%$ (30 profiles).

In terms of the rank of the researchers, 63\% (81/129) of researchers were full professors, and the percentage of associate and assistant professors were similar (19\% and 18\% respectively), as can be seen in Table 2. In order to find if there is a difference in the presence on APWs by faculty rank, we compared presence rates of the three ranks. The presence rate was $82 \%$ for assistant professor, $76 \%$ for associate professor, and 78\% for full professor, which did not differ significantly (Chi-square test, $p=0.84$ ). 
Table 2. The presence on APW by department and by rank.

\begin{tabular}{|c|c|c|c|c|c|c|}
\hline Department & $\begin{array}{c}\text { No. of } \\
\text { faculty } \\
\text { members }\end{array}$ & $\begin{array}{c}\text { No. of faculty } \\
\text { with at least } \\
\text { one academic } \\
\text { profile (\%) }\end{array}$ & $\begin{array}{c}\text { No. of faculty } \\
\text { on } \\
\text { ResearchGate }\end{array}$ & $\mid \begin{array}{c}\text { No. of faculty } \\
\text { on } \\
\text { Academia.edu }\end{array}$ & 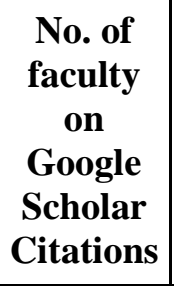 & $\begin{array}{c}\text { No. of } \\
\text { faculty } \\
\text { on } \\
\text { ORCID }\end{array}$ \\
\hline Biology & 24 & 18 (75\%) & 16 & 4 & 11 & 5 \\
\hline Chemistry & 20 & $13(65 \%)$ & 6 & 1 & 5 & 6 \\
\hline Computer Science & 25 & 24 (96\%) & 19 & 13 & 19 & 8 \\
\hline Geological Science & 18 & $14(78 \%)$ & 13 & 6 & 10 & 5 \\
\hline $\begin{array}{l}\text { Mathematics \& } \\
\text { Statistics }\end{array}$ & 19 & $13(68 \%)$ & 12 & 1 & 5 & 4 \\
\hline $\begin{array}{l}\text { Physics \& } \\
\text { Engineering } \\
\text { Physics }\end{array}$ & 23 & $18(78 \%)$ & 15 & 5 & 12 & 10 \\
\hline \multicolumn{7}{|c|}{ Rank } \\
\hline Assistant Professor & 23 & $19(82 \%)$ & 16 & 2 & 15 & 4 \\
\hline $\begin{array}{l}\text { Associate } \\
\text { Professor }\end{array}$ & 25 & $19(76 \%)$ & 13 & 8 & 11 & 9 \\
\hline Professor & 81 & $63(78 \%)$ & 52 & 20 & 36 & 25 \\
\hline Total & 129 & 100 (78\%) & 81 & 30 & 62 & 38 \\
\hline
\end{tabular}

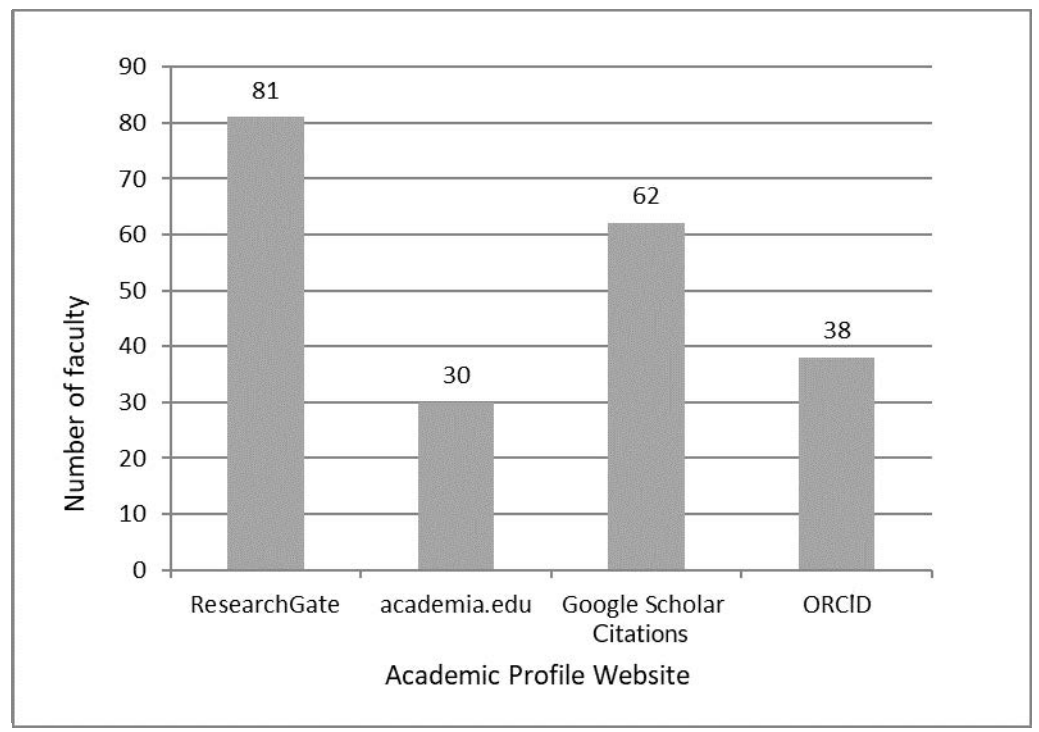

Figure 1 . Number of faculty members by APW. 
We compared the presence rate on each APW by department to find if there is a difference in the preference of APW by researchers in different disciplines. As can be seen from Figure 2, ResearchGate was the most popular platform among all disciplines, and Google Scholar Citations was the second in each of the 6 departments except in Chemistry, where ORCID ranked the second. In Computer Science, Google Scholar was as popular as ResearchGate (76\%). In Chemistry and Mathematics \& Statistics, only about 5\% of the researchers have set up a profile on Academia.edu.

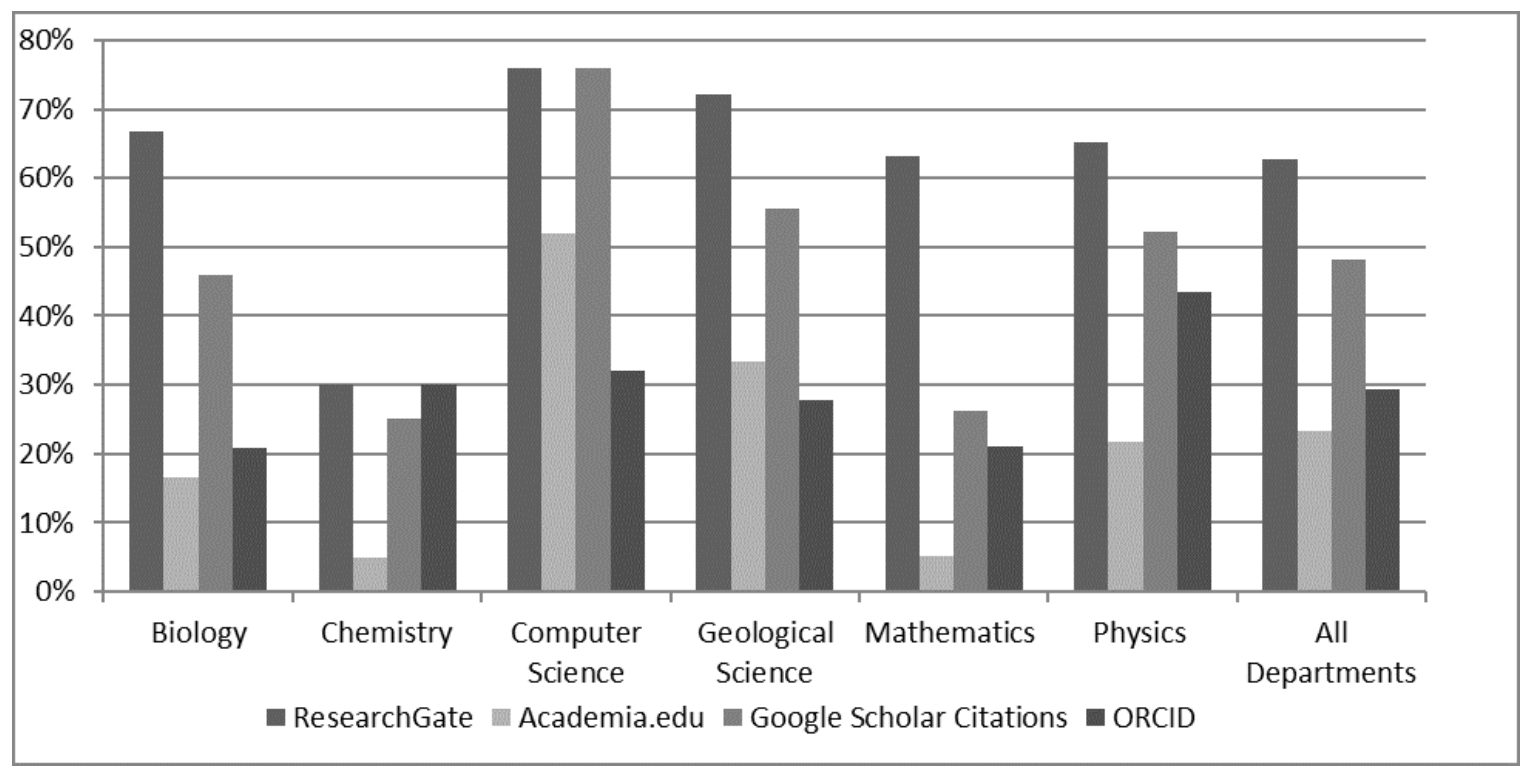

Figure 2. Percentage of profiles in each APW by department.

\section{Multiple Profiles}

In order to find out how many profiles a researcher is willing to maintain, we compared the overlap of the four profile websites. We found that, out of the 100 researchers who had established at least one profile, 34 had only one profile, 31 had two profiles, 25 had three profiles, and only 10 had four profiles. It seems that researchers are more willing to maintain one or two profiles. When they establish only one profile, 18 researchers chose ResearchGate, 9 Google Scholar, 6 ORCID, and only 1 chose Academia.edu. When they established two profiles, they were more likely to use ResearchGate and Google Scholar (17 researchers had established a profile both in ResearchGate and in Google Scholar Citations).

\section{Publications}

As can be seen in Table 3, the average number of publications listed was the highest in Google Scholar Citations (129), followed by ResearchGate (101). The average number of publications in Academia.edu or ORCID was considerably lower, with 42 and 38 on each site. 
Table 3. Average number of publications per faculty listed on each APW by department.

\begin{tabular}{|l|l|l|l|l|}
\hline Department & $\begin{array}{c}\text { Average No. of } \\
\text { Publications/faculty } \\
\text { on ResearchGate }\end{array}$ & $\begin{array}{c}\text { Average No. of } \\
\text { Publications/faculty } \\
\text { on Academia.edu }\end{array}$ & $\begin{array}{c}\text { Average No. of } \\
\text { Publications/faculty } \\
\text { on Google Scholar } \\
\text { Citations }\end{array}$ & $\begin{array}{c}\text { Average No. of } \\
\text { Publications/faculty } \\
\text { on ORCID }\end{array}$ \\
\hline Biology & 55 & 4 & 80 & 22 \\
\hline Chemistry & 72 & 1 & 48 & 58 \\
\hline $\begin{array}{l}\text { Computer } \\
\text { Science }\end{array}$ & 107 & 49 & 155 & 43 \\
\hline $\begin{array}{l}\text { Geological } \\
\text { Science }\end{array}$ & 151 & 63 & 175 & 105 \\
\hline $\begin{array}{l}\text { Mathematics } \\
\text { \& Statistics }\end{array}$ & 32 & 25 & 32 & 9 \\
\hline $\begin{array}{l}\text { Physics \& } \\
\text { Engineering } \\
\text { Physics }\end{array}$ & 168 & 45 & $\begin{array}{l}129 \\
(\text { Median:35; SD:52) }\end{array}$ & $\begin{array}{l}\text { SD:114) } \\
\text { SD: }\end{array}$ \\
\hline $\begin{array}{l}\text { All } \\
\text { Departments }\end{array}$ & $\begin{array}{l}\text { (Median:59; } \\
\text { SD:106) }\end{array}$ & $\begin{array}{l}109 \\
\text { (Median:4; SD:64) }\end{array}$ \\
\hline
\end{tabular}

'The average number of publications/faculty in all departments is the sum of the number of faculty members' publications on a specific APW, divided by the number of faculty members on that APW (see Table 2).

Of the total 211 profiles created on any of the 4 APWs, 19 (9\%) did not provide any publication or other detailed information, potentially meaning that the profile is merely symbolic and these researchers did not use APWs as a way to showcase or communicate their work. Details on researchers with only a symbolic presence on each APW are shown in Table 4. Google Scholar had the lowest symbolic profile rate; all researchers with a profile in Google Scholar had a list of publications. ORCID has the highest percentage of symbolic profiles; 35\% of researchers who had a profile on ORCID did not have any publication listed.

Table 4. Symbolic profiles on each APW.

\begin{tabular}{|c|l|l|l|l|l|}
\hline & ResearchGate & Academia.edu & $\begin{array}{c}\text { Google Scholar } \\
\text { Citations }\end{array}$ & ORCID & Total \\
\hline No. of Profiles & 81 & 30 & 62 & 38 & 211 \\
\hline $\begin{array}{c}\text { No. of Symbolic } \\
\text { Profiles (\%) }\end{array}$ & $2(2 \%)$ & $3(10 \%)$ & $0(0 \%)$ & $\begin{array}{l}14 \\
(35 \%)\end{array}$ & $\begin{array}{l}19 \\
(9 \%)\end{array}$ \\
\hline
\end{tabular}




\section{Social Activities}

We examined the social activities on the two ASNs: ResearchGate and Academia.edu. Comparing the median of the number of views, followers, and following from the two platforms, we found that these functions were used much more frequently in ResearchGate than in Academia.edu (See Table 5). The results indicate that these science researchers were more active on ResearchGate.

Table 5. Median of views, followers and following in ResearchGate and Academia.edu by rank.

\begin{tabular}{|l|l|l|l|l|l|l|}
\hline & \multicolumn{3}{|c|}{ ResearchGate } & \multicolumn{3}{c|}{ Academia.edu } \\
\hline \multicolumn{1}{|c|}{ Rank } & Views & Followers & Following & Views & Followers & Following \\
\hline Assistant Professor & 1513 & 67 & 35 & 12 & 3 & 1 \\
\hline Associate Professor & 2350 & 59 & 27 & 183 & 12 & 4 \\
\hline Professor & 3916 & 95 & 17 & 183 & 15 & 5 \\
\hline All ranks & 3036 & 76 & 23 & 178 & 12 & 4 \\
\hline
\end{tabular}

Using the categorization method developed by Yan et al. (2018), we further compared the follower-following ratio based on the data provided by ResearchGate. In this method, the follower-following ratio was used as a reflection of scholarly reputation, popularity, and academic influence. With the threshold values of follower-following ratio between $1 / 3$ and 3 , the users of the ASN are categorized into three groups:

Information Source (ratio $\geq 3$ ): users who demonstrate the highest level of reputation, popularity, and influence

Friend $(1 / 3<$ ratio $<3)$ : users who take the middle level of reputation, popularity, and influence

Information Seeker (ratio $\leq 1 / 3$ ): users who are mainly interested in obtaining academic resources and seeking interaction and hold the lowest level of reputation, popularity, and influence

We calculated the follower-following ratios of those who have established a profile in ResearchGate, excluding the 4 researchers without any followers or following. The results are listed in Table 6. There were 51 (66\%) researchers in the Information Source group, 26 (34\%) in Friend group, and none in the Information Seeker group. We also compared the three information behaviour groups in terms of rank. It was found that full professors were more likely to be Information Source, as compared to associate or assistant professor (Chi-Square test, $p=$ 0.0055); however, the difference between an assistant and an associate professor was not significant (Chi-Square test, $p=0.38$ ). 
Table 6. Number of users in Information Source, Friend, and Information Seeker groups.

\begin{tabular}{|l|l|l|l|}
\hline \multicolumn{1}{|c|}{ Rank } & Information Source & Friend & Information Seeker \\
\hline Assistant Professor & 6 & 10 & 0 \\
\hline Associate Professor & 7 & 6 & 0 \\
\hline Professor & 38 & 10 & 0 \\
\hline All rank & 51 & 26 & 0 \\
\hline
\end{tabular}

We found that other social interaction functions (i.e., questions asked and questions answered) provided by ResearchGate were rarely used: only 1 researcher asked a question, and 5 answered a question.

\section{Discussion}

In this study, we explored the presence of science researchers from the science departments of USask on APWs. We found that 78\% of the researchers established at least one academic profile. The presence rate identified in this study is higher than those reported in previous studies (MasBleda et al. 2014; Mikki et al. 2015; Ortega 2015b; Míguez-González et al. 2017; Martín-Martín et al. 2018). A few reasons might explain the differences. First, our study was conducted in 2018, later than those previously published studies. During this period, APWs may have become better known in academic world, and thus probably are more accepted by researchers. Second, to the best of our knowledge, this study is the first of its kind that targeted Canadian researchers. Canada is the world's second-largest country by total area, and research universities in this country are geographically widely dispersed. Therefore, online interactions might be more important for Canadian researchers. As such, they are more likely to use APWs as a way to display their research work and communicate with their peers.

In terms of the ranking of the popularity of the four platforms, we found that ResearchGate (61\%) was the most popular platform, Google Scholar Citations (48\%) the second, followed at some distance by ORCID (29\%) and Academia.edu (23\%). When comparing the activities of researchers on the two ASNs, we found that ResearchGate attracted more traffic than Academia.edu, as evidenced by the median of the number of publications, views, followers, and following. The results confirm previous literature findings that ResearchGate is used most often by science researchers, and Academic.edu is not popular among researchers in these disciplines (Ortega 2015b).

In recent years, there have been some controversies surrounding ASNs. Although the presence rate of ResearchGate was the highest among the four profile websites investigated in this study, the aggressive marketing strategy of ResearchGate has been identified as one the reasons of its high presence rate (Van Noorden 2014), and researchers may find the frequent emails sent by ResearchGate annoying. Full-text downloading is one of the most important reasons for researchers to use ResearchGate (Meishar-Tal \& Pieterse 2017; Wu et al. 2017), but the recent legal proceedings against ResearchGate for copyright infringement by publishers (Else 2018) may reduce the availability of full-text on ResearchGate. Further, researchers themselves who 
upload to and/or download from ResearchGate may also violate copyright laws. In addition, as the open access movement gains momentum, it becomes better known that depositing full-text in ASNs does not comply with open access mandates (Government of Canada 2016). On the other hand, ResearchGate as a platform for scholarly communication has gained some recognition from publishers. For example, Springer Nature and ResearchGate started a pilot content sharing project, automatically adding the full-text of articles published in 23 Nature-branded journals from 2017 to ResearchGate profiles (Springer Nature Group 2019). This project has received positive feedback from researchers. What effects do these issues and activities have on researchers' perception and use of ASNs? A future study may be warranted to explore the impact of these factors on ResearchGate.

Creating and updating academic profiles requires researchers investing their time and effort, extra work added to their busy research schedule. As various APWs are available, the question is, how many profiles is a researcher willing to maintain? Our results indicated that researchers at USask were more willing to maintain one or two profiles, which aligns with previous research findings that researchers were reluctant to maintain multiple profiles (Mikki et al. 2015; Ortega 2015c). As pointed out by Allen (2017), the burden of maintaining multiple profiles has created the problem called "profile fatigue." To reduce the fatigue of researchers, it is best to have a profile system that is interoperable with researchers' standard work processes, such as grant application and manuscript submission. In this regard, ORCID is uniquely positioned to meet this goal. ORCID allows researchers to incorporate their IDs in the processes of manuscript submission and funding application, which saves their time by avoiding entering the same information (e.g., previous publications) repeatedly. Therefore, it makes sense to advocate that every active researcher should have an ORCID profile.

It was noted that, although ORCID is a relatively new profile platform, 29\% of the researchers had established a profile on this platform, a rate much higher than the rate of 3-15\% reported in previous literature (Mikki et al. 2015; Tran \& Lyon 2017). In recent years, many efforts have been made to promote ORCID. For example, many university libraries have developed LibGuides to introduce ORCID, and many publishers and funding agencies encourage researchers to provide their ORCID numbers when submitting manuscripts or grant applications. Particularly in Canada, ORCID-CA has also been established to facilitate the application of ORCID in research institutions. The results of this study provide encouraging evidence of the success of these efforts. However, we noticed a high percentage of symbolic profiles in ORCID (35\%), which is much higher than that in ResearchGate (2\%) or Google Scholar Citations (0\%). Data from the ORCID website also shows that only $25 \%(1,914,120 / 7,656,300)$ of active ORCID profiles have publications listed (ORCID 2019a), indicating symbolic profile presences are common across the platform. It is possible that researchers set up their ORCID accounts when prompted by publishers or funding agencies during manuscript submission or grant application processes, but they never returned to add their publications to their profiles. Without a complete list of publications, it is difficult to fulfill ORCID's mission of name disambiguation. As Mikki et al. (2015) pointed out, the success of an APW mainly depends on how easy it is to incorporate into the researchers' current work processes. While future publications can be added automatically to researchers' ORCID profiles, if they provide their ORCID numbers when submitting manuscripts, the process of adding previous publications to ORCID profiles is not straightforward. ORCID provides several options for this work: link to works listed in 
ResearcherID of Web of Sciences or Scopus Author ID, search works indexed in external databases, import a BibTex file, or add manually. These steps might not be intuitive or be seen as extra work for researchers. On the contrary, in ResearchGate or Google Scholar Citations, once a researcher creates an account, it will automatically provide a list of his/her potential publications for the researcher to add to the profile. Our results suggest that it may be necessary to develop a similar function in ORCID to better streamline the work process and to make it easier for researchers to add publications to their profiles. This finding also has implications for librarians. In order for ORCID to be more effective, librarians may consider providing specific instructions to researchers on how to add publications to their ORCID profiles from various sources.

One of the main features of ASNs is the social networking function designed to enhance collaboration and knowledge sharing among researchers. However, our study found that ASNs were used mainly for showcasing researchers' publications, and, to a lesser extent, for tracking the developments and trends in their research disciplines. Further, they were seldom used for discussion or interaction, as evidenced by the fact that only 6 questions were asked or answered among the 81 researchers who have a profile in ResearchGate, which aligns with findings in previous literature. Meier and Tunger (2018) found that only 19\% of ResearchGate users in physics, biology, medicine, and neuroscience had asked a question, and $49 \%$ had provided an answer. Shrivastava and Mahajan (2017) also found that only 12\% of the physics researchers in an Indian university asked or answered a question. The evidence from these studies indicates that interactive functions are not well-used by science researchers. Active involvement in academic social networking requires researchers to invest considerable time and effort. Given the busy schedule of academic researchers, the results seem to suggest that social interaction may not be an essential function for science researchers. Further study needs to be conducted to find why these functions were not used. Recently, the non-transparent and easily manipulated metrics provided by ResearchGate, RG Score, has caused concerns to the academic community (OrdunaMalea et al. 2017). There are also criticisms of ResearchGate and Academia.edu for exploiting researchers' data (Bond 2017). If such study is done in the future, it might consider exploring if these factors play a role in the low usage of the social interaction functions on ASNs.

It is commonly believed that young people are more engaged in general social media. However, the limited previous research investigating age differences in the use of social media for scholarly communications produced mixed results (Nicholas and Rowlands 2011; Tenopir et al. 2013; Mikki et al. 2015). In our study, we also did not find a significant difference in ResearchGate participation among assistant, associate, and full professors (Chi-square test, $p=$ 0.41). This result confirms previous findings, that, given the wide adoption of social media applications in the last decade, age is probably no longer a significant indicator for the participation of social media in the research world (Nicholas \& Rowlands 2011). On the other hand, we found somewhat different behaviours in terms of how the ASNs were used. Based on the follower-following ratio, we found that full professors were more likely to be Information Source type users, and associate or assistant professors are more likely to be Friend type users. The results confirm that the follower-following ratio could be used as a proxy to the reputation and influence of researchers, as suggested by Yan et al. (2018).

This study has two major limitations. First, we used the science faculty at USask as a sample, and the results might not be generalizable to other disciplines or other institutions. Second, we 
identified that social interaction functions provided by ASNs (e.g., asking and answering questions) were not well used, but it is unknown to what extent ASNs have been used for other functions such as requesting or providing full-text, because this information is not publicly available. A further study might be necessary to have a complete understanding of the usage of ASNs.

\section{Conclusion}

Our study found that most of the science researchers at USask had established at least one academic profile, with ResearchGate being the most popular, Google Scholar Citations second, followed by ORCID and Academia.edu. Since 22\% of researchers have not established any academic profile, we plan to have more outreach activities to ensure researchers create at least one profile.

ORCID, as a unique persistent author identifier, can save researchers valuable time when incorporated into their research processes, and it is recommended that each researcher have an ORCID profile (ORCID-CA 2019). However, the uptake rate of ORCID found in this study was $29 \%$, much lower than that of ResearchGate (63\%) and Google Scholar Citations (48\%). When comparing the rate of symbolic profiles, we found that $35 \%$ of the ORCID profiles did not have any publications, a rate also higher than that on the other three platforms. Without a complete list of publications, it would be challenging for ORCID to reach its goal for name disambiguation. Our results suggest that more efforts are needed to encourage researchers to take full advantage of ORCID. Specifically, the workflow in ORCID could be improved to make it more straightforward for researchers to add their publications to their profiles. The results also speak to a need for education. In order to improve the effectiveness of ORCID, librarians may consider providing specific instructions on how to add publications to ORCID profiles from different sources as part of their promotional campaign.

ResearchGate had the highest presence rate of the four APWs examined in this study, but it should be noted that there are several controversial issues surrounding ASNs, such as copyright infringement, its aggressive marketing strategies, usage data exploitation, and open access noncompliance. On the other hand, ResearchGate as a platform connecting researchers has received some recognition by publishers as evidenced by the recent pilot full-text content sharing project between Springer Nature and ResearchGate. Although ASNs provide functions for academic social networking in addition to regular profile service, we found these social interaction functions were not well adopted by science researchers. Further research is needed to find out if the future usage of ResearchGate changes as researchers become more aware of the issues around ASNs, and to identify the essential needs of researchers for knowledge sharing and research collaboration, thus improving the functionalities of APWs.

\section{Acknowledgements}

This study was funded by President's SSHRC Research Fund, University of Saskatchewan. The authors thank Maha Kumaran for valuable feedback to the manuscript. 


\section{References}

Academia.edu. 2019. About. [accessed 2019 Dec 12]. Available from http://www.academia.edu/about.

Allen E. 2017. Researcher \#profilefatigue - what it is and why it's exhausting! In ScienceOpen Blog. [accessed 2020 Apr 16]. Available from https://blog.scienceopen.com/2014/09/researcherprofilefatigue-what-it-is-and-why-its-exhausting/.

Becher T. 1989. Academic Tribes and Territories: Intellectual Enquiry and the Cultures of Disciplines. Stony Stratford: The Society for Research into Higher Education \& Open University Press.

Bond S. 2017. Dear Scholars, Delete Your Account At Academia.Edu. Forbes. [accessed 2020 Apr 16]. Available from https://www.forbes.com/sites/drsarahbond/2017/01/23/dear-scholarsdelete-your-account-at-academia-edu/\#6bb0fd5b2d62.

Else H. 2018. Major publishers sue ResearchGate over copyright infringement. Nature. DOI: 10.1038/d41586-018-06945-6.

Government of Canada. 2016. Tri-Agency Open Access Policy on Publications. [accessed 2020 Jul 3]. Available from https://www.ic.gc.ca/eic/site/063.nsf/eng/h_F6765465.html.

Gruzd A. \& Goertzen M. 2013. Wired academia: Why social science scholars are using social media. In: Proceedings of the Annual Hawaii International Conference on System Sciences. p. 3332-3341.

Haak L.L., Fenner M., Paglione L., Pentz E. \& Ratner H. 2012. ORCID: A system to uniquely identify researchers. Learned Publishing. 25(4):259-264. DOI: 10.1087/20120404.

Harington R. 2017. ResearchGate: Publishers Take Formal Steps to Force Copyright Compliance. [accessed 2020 Apr 15]. Available from https://scholarlykitchen.sspnet.org/2017/10/06/researchgate-publishers-take-formal-steps-forcecopyright-compliance/.

Kjellberg S. \& Haider J. 2018. Researchers' online visibility: tensions of visibility, trust and reputation. Online Information Review. DOI: 10.1108/OIR-07-2017-0211.

Martín-Martín A., Orduna-Malea E. \& Delgado López-Cózar E. 2018. Author-level metrics in the new academic profile platforms: The online behaviour of the Bibliometrics community. Journal of Informetrics. 12(2):494-509. DOI: 10.1016/j.joi.2018.04.001.

Mas-Bleda A., Thelwall M., Kousha K. \& Aguillo I.F. 2014. Do highly cited researchers successfully use the social web? Scientometrics. 101(1):337-356. DOI: 10.1007/s11192-014$\underline{1345-0 .}$ 
Meier A. \& Tunger D. 2018. Survey on opinions and usage patterns for the ResearchGate platform. PLoS One. 13(10). DOI: 10.1371/journal.pone.0204945.

Meishar-Tal H. \& Pieterse E. 2017. Why Do Academics Use Academic Social Networking Sites? International Review of Research in Open and Distributed Learning. 18(1). DOI: 10.19173/irrodl.v18i1.2643.

Míguez-González M.I., Puentes-Rivera I. \& Dafonte-Gómez A. 2017. Academic social networks and communication researchers from universities in the north of Portugal: An analysis of Academia.edu and ResearchGate. In: Freire F.C, Araújo XR, Fernández VAM, García XL, editors. Media and Metamedia Management. Cham, Switzerland: Springer. p. 405-411. DOI: 10.1007/978-3-319-46068-0_53.

Mikki S., Zygmuntowska M., Gjesdal Y.L. \& Ruwehy H.A.A. 2015. Digital presence of norwegian scholars on academic network sites-where and who are they? PLoS One. 10(11). DOI: 10.1371/journal.pone.0142709.

Nicholas D. \& Rowlands I. 2011. Social media use in the research workflow. Information Services \& Use. 31(1/2):61-83. DOI: 10.1087/20110306.

Van Noorden R. 2014. Online Collaboration: Scientists and the social network. Nature. 512(7513):126. DOI: 10.1038/512126a.

ORCID-CA. 2019. About ORCID-CA. [accessed 2019 Dec 13]. Available from https://orcidca.org/about.

ORCID. 2018. How is ORCID different from other researcher identifiers? [accessed $2020 \mathrm{Apr}$ 16]. Available from https://support.orcid.org/hc/en-us/articles/360006972453-How-is-ORCIDdifferent-from-other-researcher-identifiers-.

ORCID. 2019a. ORCID Statistics. [accessed 2019 Dec 12]. Available from https://orcid.org/statistics.

ORCID. 2019b. ORCID Member Organizations. [accessed 2019 Dec 12]. Available from https://orcid.org/members.

Orduna-Malea E., Martín-Martín A., Thelwall M. \& Delgado López-Cózar E. 2017. Do ResearchGate Scores create ghost academic reputations? Scientometrics. 112(1):443-460. DOI: 10.1007/s11192-017-2396-9.

Ortega J.L. 2015a. Google Scholar Citations 2015 report. Scientific Web Observer. [accessed 2020 Apr 22]. Available from http://swobserver.blogspot.com/2015/02/google-scholar-citation2015-report.html.

Ortega J.L. 2015b. Disciplinary differences in the use of academic social networking sites. Online Information Review. 39(4):520-536. DOI: 10.1108/OIR-03-2015-0093. 
Ortega J.L. 2015c. Relationship between altmetric and bibliometric indicators across academic social sites: The case of CSIC's members. Journal of Informetrics. 9(1):39-49. DOI:

10.1016/j.joi.2014.11.004.

ResearchGate. 2019. About. [accessed 2019 Dec 12]. Available from https://www.researchgate.net/about.

Shrivastava R. \& Mahajan P. 2017. An altmetric analysis of ResearchGate profiles of physics researchers: A study of University of Delhi (India). Performance Measurement and Metrics. 18(1):52-66. DOI: 10.1108/PMM-07-2016-0033.

Springer Nature Group. 2019. Springer Nature and ResearchGate extend content sharing pilot following positive feedback. [accessed 2020 Apr 16]. Available from https://group.springernature.com/de/group/media/press-releases/springer-nature-andresearchgate-extend-content-sharing-pilot/16916562.

Tenopir C., Allard S., Levine K., Volentine R., Christian L., Boehm R., Nichols F., Christensen R., Nicholas D., Watkinson A. et al. 2013. Trust and Authority in Scholarly Communications in the Light of the Digital Transition. Prepared for Alfred P. Sloan Foundation. [accessed 2018 Dec 25]. Available from http://ciber-research.eu/download/20140115Trust_Final_Report.pdf.

Tran C.Y. \& Lyon J.A. 2017. Faculty use of author identifiers and researcher networking tools. College and Research Libraries. 78(2):171-182. DOI: 10.5860/crl.78.2.171.

U15. 2019. Group of Canadian Research Universities. [accessed 2019 Dec 13]. Available from http://u15.ca/.

Wu S., Stvilia B. \& Lee D.J. 2017. Readers, Personal Record Managers, and Community Members: An Exploratory Study of Researchers' Participation in Online Research Information Management Systems. Journal of Library Metadata. 17(2):57-90. DOI: 10.1080/19386389.2017.1348783.

Yan W., Zhang Y. \& Bromfield W. 2018. Analyzing the follower-followee ratio to determine user characteristics and institutional participation differences among research universities on ResearchGate. Scientometrics. 115(1):299-316. DOI: 10.1007/s11192-018-2637-6. 